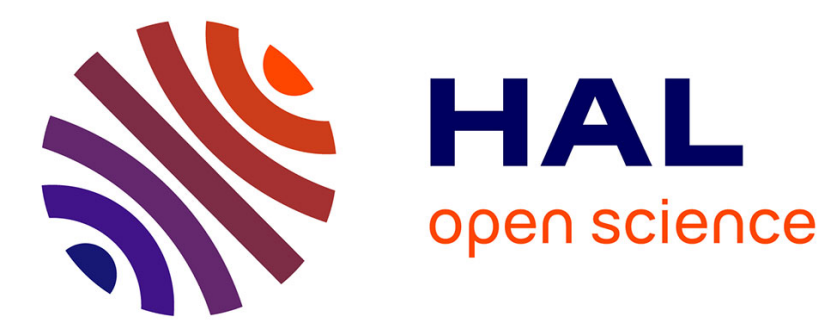

\title{
Total ozone measurements and stratospheric cloud detection during the AASE and the TECHNOPS Arctic Balloon Campaign
}

\author{
Franck Lefèvre, D. Cariolle
}

\section{- To cite this version:}

Franck Lefèvre, D. Cariolle. Total ozone measurements and stratospheric cloud detection during the AASE and the TECHNOPS Arctic Balloon Campaign. Geophysical Research Letters, 1991, 18 (1), pp.33-36. 10.1029/90GL02600 . hal-02896838

\section{HAL Id: hal-02896838 \\ https://hal.science/hal-02896838}

Submitted on 30 Apr 2021

HAL is a multi-disciplinary open access archive for the deposit and dissemination of scientific research documents, whether they are published or not. The documents may come from teaching and research institutions in France or abroad, or from public or private research centers.
L'archive ouverte pluridisciplinaire HAL, est destinée au dépôt et à la diffusion de documents scientifiques de niveau recherche, publiés ou non, émanant des établissements d'enseignement et de recherche français ou étrangers, des laboratoires publics ou privés. 
GEOPHYSICAL RESEARCH LETTERS, VOL. 18, NO. 1, PAGES 33-36, JANUARY 1991

\title{
TOTAL OZONE MEASUREMENTS AND STRATOSPHERIC CLOUD DETECTION DURING THE AASE AND THE TECHNOPS ARCTIC BALLOON CAMPAIGN.
}

\author{
F. Lefèvre and D. Cariolle
}

Météo France, Centre National de Recherches Météorologiques, Toulouse

\begin{abstract}
Total ozone fields over Northern Europe and Arctic regions were calculated during the winter 1989 using the TOVS/HIRS2 infra-red radiances. During that same period ground-based and airborne ozone and PSCs measurements were performed as part of the AASE and TECHNOPS campaigns. Comparisons have also been made with the TOMS ozone data. They show a generally good agreement, except above northernmost regions where TOMS observations seem affected by the high solar zenith angles encountered near the polar night region. This result is confirmed by the ozone measurements made from Kiruna on the 23 and 30 of January. A major type II PSC event is clearly identified in the TOVS ozone field on January 31. The cloud location is consistent with airborne lidar soundings made on the same day from DC-8 aircraft, which measured scattering and depolarization ratios characteristic of high concentration of large ice crystals. TOVS observations show that type II PSCs covering large areas may form above the Arctic regions. However, only two major water-ice PSCs events have been identified from January 3 to February 10 . These events may not be frequent enough for the polar air to reach a completely processed state, with high $\mathrm{ClO}$ amounts and significant denitrification as it is observed in the Antarctic early spring.
\end{abstract}

\section{Introduction}

The Airborne Arctic Stratospheric Expedition (AASE, Turco et al., 1990) and the balloon campaign at Kiruna (Hofmann et al., 1989, Kondo et al., 1990) were conducted during the winter 1988-1989 to determine the possible existence of chemical processes that could destroy ozone in the winter-time Arctic stratosphere. Observations made from the ER-2 aircraft showed that the polar vortex was primed to ozone destruction, with $\mathrm{ClO}$ mixing ratios sometimes as high as in Antarctica (Brune et al., 1990). Measurements of nitrogen species suggested also large chemical perturbations of the Arctic stratosphere, in relation with Polar Stratospheric Clouds (PSCs) formation.

Total ozone data have been derived in JanuaryFebruary 1989 using our algorithm and the radiances measured by the TOVS/High resolution Infra-Red Sounder on board the NOAA-10 satellite. Similar data processed during the formation of the 1987 "ozone hole" have shown that our total ozone determinations are in good agreement with the ozonesondes launched from

Copyright 1991 by the American Geophysical Union.

Paper number 90GL02600

0094-8534/90/90GL-02600\$03.00 the Antarctic stations (Lefère et al., 1990). The extensive campaigns conducted in 1989 over Scandinavia give a further opportunity to check the accuracy of our retrievals for the situations with higher ozone contents that are encountered in the northern polar latitudes. We report also the observation of a major PSC type II event clearly identified in the TOVS total ozone field on January 31, 1989.

\section{Method}

Total ozone is derived using a physical retrieval algorithm described in detail by Lefèvre et al. (1990). The approach is to infer the total column from the ozone transmittance at 9.6 microns above $400 \mathrm{hPa}$. For this purpose, a concept of mean temperature of the ozone layer (TO3) is introduced and computed from radiances given by four appropriate HIRS2 channels. The ozone transmittance is computed using the brightness temperatures at 9.6 and 11.1 microns (surface), and TO3. The ozone column is then calculated from the transmittance at 9.6 microns and the temperature TO3. Coefficients used in the retrieval have been calculated from regressions against a large set of ozone, temperature and water vapor profiles measured at mid and high latitudes. In order to prevent the negative impact of cold clouds on the retrievals, a threshold contrast of $20^{\circ} \mathrm{K}$ is required between the surface temperature and TO3. Because of this limitation, total ozone is not computed above most of the high tropospheric clouds, like cirrus or cumulonimbus. With this restriction, the overall precision on total ozone data is about $5-6 \%$.

TOVS ozone data have been compared in January and February of 1989 with the TOMS measurements supplied by the NSSDC (level 5 of the TOMS algorithm). An example is given by the maps obtained from both instruments on February 8 (Figure 1). A good agreement is found in the mid-latitudes and over South Scandinavia, with a rather homogeneous ozone field over Western Europe and a high ozone tongue extending SW from Scotland. However at higher latitudes, high ozone values are calculated by TOVS up to the Spitzberg, while TOMS observes a strong ozone decrease near the polar night region. It is very unlikely that a physical mechanism could explain the existence of the sharp gradient measured by TOMS. In particular no dynamical patterns could account for the maintenance of this structure. In this region TOVS determinations are 40-60 DU higher than TOMS, which seems to suffer from the lack of intense sunlight at these latitudes. The high TOMS ozone values above Iceland probably result from the advection of ozone-rich air between the two measurements that are made 4 hours apart.

Using a gridding scheme designed to minimize the 

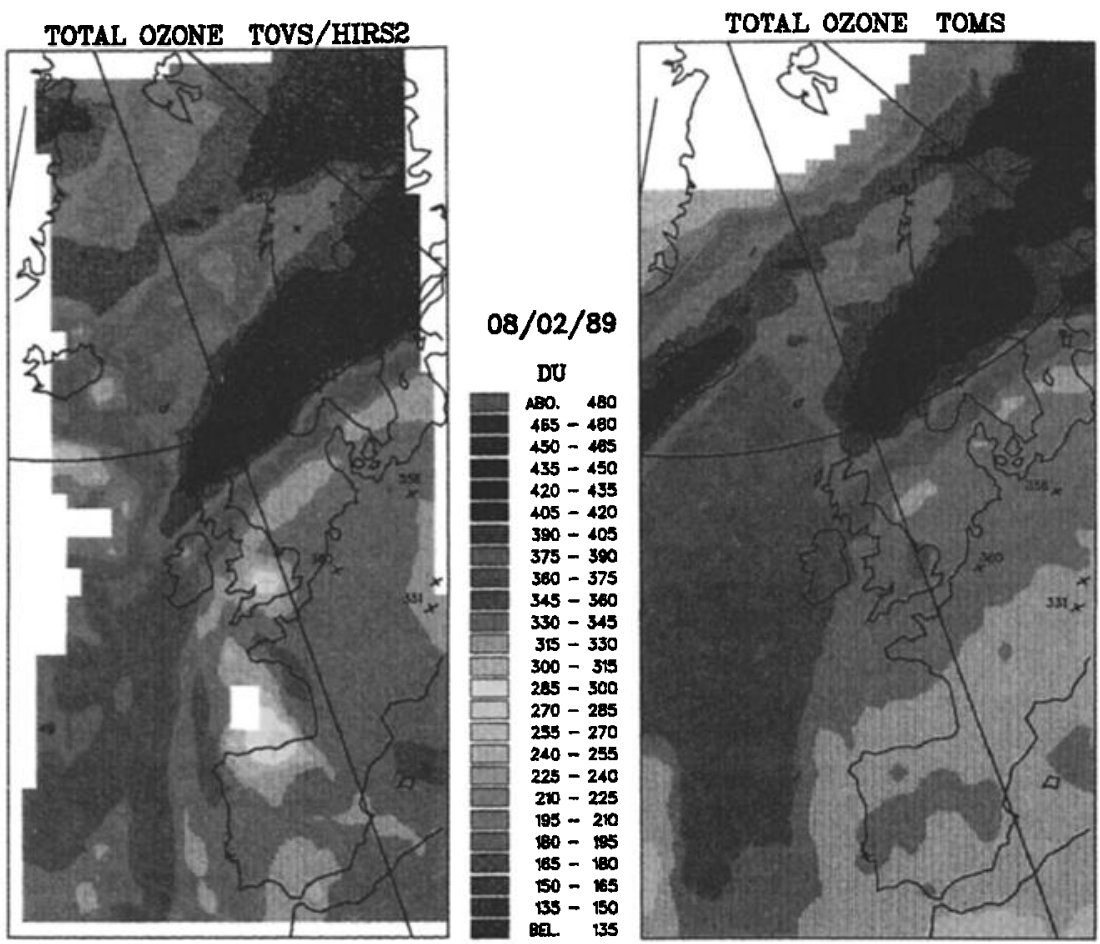

Fig.1. Total ozone distribution for February 8, 1990. Left: TOVS/HIRS2. Right: TOMS.

effects of displacements between the two observations, more than 4300 ozone determinations have been compared during the period of the campaign. The dependence on solar zenith angle (SZA) of the difference between TOVS and TOMS ozone amounts is shown in Figure 2. A good agreement is found in the mid-latitudes (SZA low), where the difference between the two instruments does not exceed $3 \%$. But a significant drift increasing with solar zenith angle (from $10 \%$ up to $14 \%$ ) is observed for SZA larger than $78^{\circ}$.

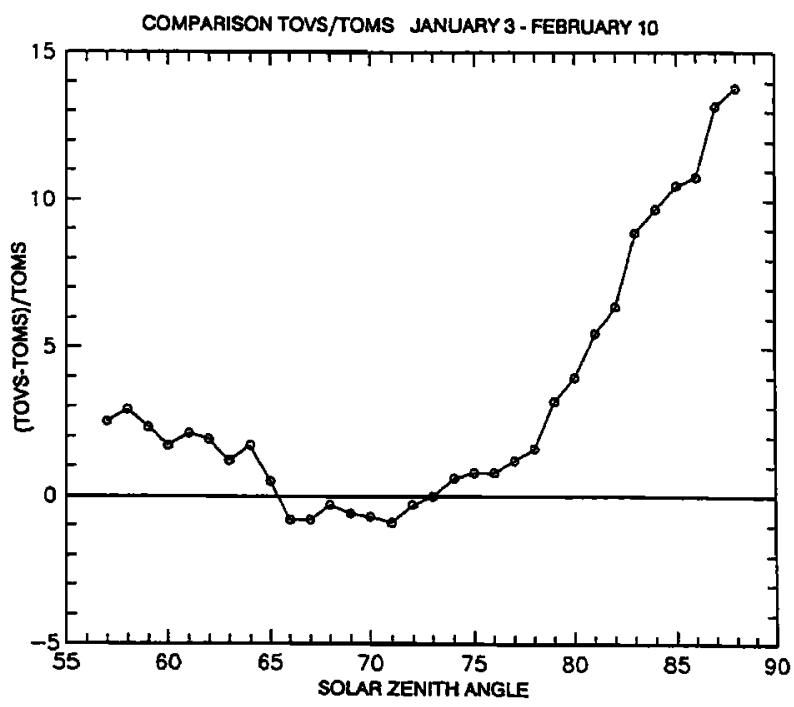

Fig.2. Comparison of total ozone data from TOVS and TOMS instruments, as a function of solar zenith angle. Since TOVS data were not available every day, the comparison is made for only 28 dates between January 3 and February 10, 1989.
This tends to confirm the TOMS underestimate observed on February 8, also recorded during the formation of the ozone hole in Antarctica (Pommereau et al., 1989; Lefèvre et al., 1990).

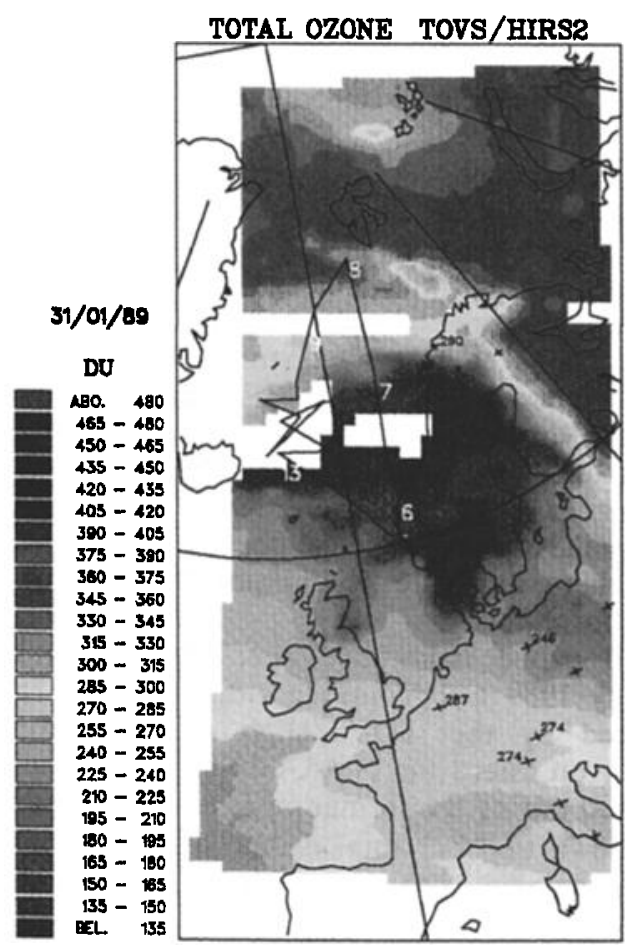

Fig.3. Total ozone distribution and flight track of the DC-8 for January 31, 1989. The grey areas, with values below 130 DU, show the regions covered by thick PSCs. Total ozone measurements by Dobson stations are also included (source: Ozone Data for the World). 
Measurements made during the TECHNOPS campaign are completely consistent with the results reported above. $330 \mathrm{DU}$ (integrated profile) and $325^{+} 25$ DU (ground-based spectrometer) were measured at Kiruna (Sweden, $68^{\circ} \mathrm{N}, 20^{\circ} \mathrm{E}$ ) on January 23 and 30 respectively (Hofmann et al., 1989). TOVS algorithm gave values of 334 and $330 \mathrm{DU}$, while only 257 and 276 DU were observed by TOMS on these two days. These results confirm the better reliability of TOVS-derived total ozone measurements in the polar latitudes, where UV techniques are affected by high solar zenith angles.

\section{PSC detection}

Because the ozone column is inferred from the ozone transmittance above $400 \mathrm{hPa}$, low tropospheric clouds do not introduce significant error in the algorithm. This is not the case for optically thick water-ice PSCs, which can strongly perturb the total ozone retrieval. Type I PSCs, composed of smaller nitric acid particles, generally do not affect the TOVS radiances. For example, TOVS measurement over Kiruna on 23 January is consistent with the balloon-borne ozone sonde, though a type I PSC was clearly detected between 19 and $22 \mathrm{~km}$ by Hofmann et al. (1989). Becoming partially the emitting surface in the infra-red, dense PSCs hide the underlying ozone and lead to low total ozone values more representative of the column above the top of the cloud. Thus type II PSCs can be easily detected by a deep minimum in the ozone field, as shown with Antarctic data by Cariolle et al. (1989).

We report in this paper a similar observation during the AASE on January 31. From January 30 to 31 , a strong minimum bounded by large gradients developed in the ozone field over the Norwegian Sea and Scandinavia (Figure 3). Ozone values inside the minimum are below 130 DU and often reach less than 100 DU. These low amounts are indications of interference between an optically thick type II PSC with the TOVS ozone retrieval. Temperature at $50 \mathrm{hPa}$ given by the ECMWF analysis shows that the cloud formed in a bulk of cold air with temperatures below $188^{\circ} \mathrm{K}$. The cloud mapping is consistent with these temperatures, which are those expected to reach the frost point.

On Figure 3 is also shown the flight track of the DC-8 used during the AASE. On January 31 it crosses the region identified from TOVS as covered by type II PSCs. McCormick et al. (1990) reported PSC observations by airborne lidar during the AASE. Both type I and type II PSCs are observed during the flight of January 31. TOVS and lidar observations are nearly coincident in time during the northbound leg of the DC-8, from Sola to $76^{\circ} \mathrm{N}$. Figure 3 shows that the DC- 8 flew inside the region covered by the type II PSC from the takeoff till 7H-7H30 GMT. During the same period, the airborne lidar recorded high scattering and depolarization ratios ( $>10$ and $=10-50 \%$ respectively) between 19 and $22 \mathrm{~km}$. These observations are the characteristics of large ice crystals, composing the type II PSCs. Lidar observations also show that the ozone contents given by the TOVS algorithm are anti-correlated with the optical thickness of the PSC. The lowest ozone contents are computed before $7 \mathrm{H}$ when the greatest scattering ratios were recorded. At the edge of the PSC detected by TOVS, scattering ratio drops rapidly to become more representative of type I PSCs, while the ozone amounts increases up to $250 \mathrm{DU}$ after $7 \mathrm{H} 15$. Observed nearly during the entire flight outside the TOVS minimum, the impact of type I PSCs on the ozone retrieval does not seem significant.

ECMWF meteorological analysis shows that the pronounced cooling observed in the low stratosphere on January 31 was associated with the penetration of a midtropospheric ridge below the polar vortex. McKenna et al. (1989) studied the possible formation of PSCs induced by strong adiabatic cooling above these anticyclonic disturbances. Low ozone columns are often encountered during these events, associated with a bulge in the isentropes and a higher tropopause. This process can certainly explain part of the sudden total ozone drop observed by the dobson instrument based at Oslo (280 DU on $01 / 30,200 \mathrm{DU}$ on $01 / 31$ ). However, these large total ozone variations and the very low value measured on January 31 seem rather unusual. Slightly outside the Northern edge of the PSC, the dobson instrument based at Tromsö recorded higher values on both days, with a loss limited to only $20 \mathrm{DU}$ ( $310 \mathrm{DU}$ on $01 / 30,290$ on 01/31). Large amounts of chlorine in a reactive form may have been released at the surface of this PSC. Because of the large size of the particles composing the type II PSCs and their fast sedimentation rate, denitrification processes can be also very efficient during these events. Furthermore, it is important to note that the type II PSC observed by TOVS formed at a latitude where there was extensive solar irradiance. Thus, as it has been observed in Antarctica (Lefevre et al., 1990), rapid ozone decrease tends to occur during or just after the formation of the type II PSCs, contributing to the low column measured by dobson instrument at Oslo. However further studies are needed to assess the relative role of dynamics, chemistry and the possible interferences of UV measurements with PSCs (all types) during the formation of these localized ozone minima.

\section{Concluding remarks}

The comparisons of TOVS and TOMS data performed during the AASE and TECHNOPS campaigns show a good agreement between the two instruments in the mid-latitudes and over South Scandinavia. In particular, the recent improvements (new calibration for mid and polar latitudes) brought to our algorithm have removed the TOVS overestimate previously reported between $50^{\circ}$ and $60^{\circ} \mathrm{N}$ by Muller and Krueger (1987). Local balloon measurements made near the night terminator confirm the accuracy of TOVS determinations, whereas the lack of intense sunlight apparently induces a significant underestimate of the ozone content given by TOMS. These results demonstrate the ability of our new algorithm to provide accurate ozone measurements from TOVS, especially in the polar night region and for high solar zenith angles. TOVS could efficiently complement the TOMS data for the next polar campaigns.

On January 31 the localization from the TOVS observations of a large area (more than $700000 \mathrm{~km}^{2}$ ) covered with type II PSC was found in complete agreement with the airborne lidar soundings. This 
surface is typical of most of the PSCs events identified by TOVS over the Antarctic during the winter 1987. Nevertheless, whereas water-ice PSCs are quasipermanent features during the Antarctic winter-time, TOVS observed major type II PSC events on only two occasions during the January-February 1989 period (Jan. 24 and Jan. 31-Feb. 1). Brune et al. (1990) measured an increase of $\mathrm{ClO}$ mixing ratios for the final ER-2 flights inside the vortex. Abundances of $\mathrm{ClO}$ reached $1100 \mathrm{pptv}$ on February 10, a few days after identification of type II PSCs. This suggests that if efficient chlorine activation occurs on more frequent type I PSC nitric acid particles, this process could be significantly increased at the surface of water ice type II PSCs.

Acknowledgments. The authors would like to thank M.Homleid (Norwegian Met. Inst.) and F.Stordal (Inst. for Geophys. of Oslo) in charge of satellite data acquisition and transmission. We thank also R.D. McPeters, A.J. Krueger (NASA/GSFC) and the National Space Science Data Center for supplying the TOMS data used in this study. This work was supported by the Programme Atmosphere Moyenne of the Centre National d'Etudes Spatiales, Centre National de la Recherche Scientifique and Secrétariat d'Etat chargé de l'Environnement (under grant 89-125), and by the Commission of European Communities (STEP 016 project).

\section{References}

Brune, W.H., D.W. Toohey, J.G. Anderson, and K.R. Chan, In situ observations of $\mathrm{ClO}$ in the Arctic stratosphere: ER-2 aircraft results from $59^{\circ} \mathrm{N}$ to $80^{\circ} \mathrm{N}$ latitude, Geophys. Res. Lett., 17, 505-508, 1990.

Cariolle, D., S. Muller, F. Cayla and M.P. McCormick, Mountain waves, polar stratospheric clouds and the ozone depletion over Antarctica, J. Geophys. Res., 94, 11233-11240, 1989.

Hofmann, D.J., T.L. Deschler, P, Aimedieu, W.A. Matthews, P.V. Johnston, Y. Kondo, W.R. Sheldon, G.J. Byrne, and J.R. Benbrook, Stratospheric clouds and ozone depletion in the Arctic during January 1989, Nature, 340, 117-121, 1989.
Kondo, Y., P. Aimedieu, W.A. Matthews, D.W. Fahey, D.G. Murcray, D.J. Hofmann, P.V. Johnston, Y. Iwasaka, A. Iwata, and W.R. Sheldon, BalloonBorne measurements of total reactive nitrogen, nitric acid, and aerosols in the cold Arctic stratosphere, Geophys. Res. Lett., 17, 437-440, 1990.

Lefèvre, F., D. Cariolle, S. Muller, and F. Karcher, Total ozone from TOVS/HIRS2 infra-red radiances during the formation of the 1987 "ozone hole", Submitted to J. Geophys. Res., 1990.

McCormick, M.P., G.S. Kent, W.H. Hunt, M.T. Osborn, L.R. Poole, and M.C. Pitts, Arctic polar stratospheric cloud observations by airborne lidar, Geophys. Res. Lett., 17, 381-383, 1990.

McKenna, D.S., R.L. Jones, J.Austin, E. Browell, M.P. McCormick, A.J. Krueger, and A.F. Tuck, Diagnostic studies of the Antarctic vortex during the 1987 Airborne Antarctic Ozone Experiment: ozone mini-holes, J. Geophys. Res., 94, 11641-11668, 1989.

Muller, S., and F.R. Cayla, Total ozone measurements derived from TOVS radiances, Planet. Space Sci., 31, 779-785, 1983.

Muller, S., and A.J. Krueger, Analysis anc comparison of ozone maps obtained by TOMS and TOVS during the MAP/GLOBUS 1983 campaign, Planet. Space Sci., 35, 539-545, 1987.

Pommereau, J.P., F. Goutail, H. LeTexier, and T.S. Jorgensen, Stratospheric ozone and nitrogen dioxide monitoring at Southern and Northern polar latitudes, Proc. of the 28th Int. Astrophys. Coll., Liège, 1989.

Turco, R., A. Plumb, and E. Condon, The Airborne Arctic Stratospheric Expedition: Prologue, Geophys. Res. Lett., 17, 313-316, 1990.

D. Cariolle and F. Lefèvre, Météo France, Centre National de Recherches Météorologiques, 42 avenue Coriolis, 31057 Toulouse Cedex, France.

\footnotetext{
(Received September 27, i990 revised November 21, 1990; accepted November 26, 1990)
} 